\title{
Gliosarcoma: distinct molecular pathways and genomic alterations identified by DNA copy number/SNP microarray analysis
}

\author{
Lindsey Lowder ${ }^{1}$ (1) - Jennifer Hauenstein ${ }^{2} \cdot$ Ashley Woods $^{3} \cdot$ Hsiao-Rong Chen $^{4} \cdot$ Manali Rupji $^{4}$ (D) Jeanne Kowalski ${ }^{5}$. \\ Jeffrey J. Olson ${ }^{6} \cdot$ Debra Saxe $^{7} \cdot$ Matthew Schniederjan $^{8} \cdot$ Stewart Neill $^{1} \cdot$ Brent Weinberg $^{9} \cdot$ Soma Sengupta $^{10}$
}

Received: 25 March 2019 / Accepted: 26 April 2019 / Published online: 9 May 2019

(c) The Author(s) 2019

\begin{abstract}
Purpose Gliosarcoma is a histologic variant of glioblastoma (GBM), and like GBM carries a poor prognosis. Median survival is less than one (1) year with less than $5 \%$ of patients alive after 5 years. Although there is no cure, standard treatment includes surgery, radiation and chemotherapy. While very similar to GBM, gliosarcoma exhibits several distinct differences, morphologically and molecularly. Therefore, we report a comprehensive analysis of DNA copy number changes in gliosarcoma using a cytogenomic DNA copy number $(\mathrm{CN})$ microarray $\left(\mathrm{OncoScan}{ }^{\circledR}\right)$.

Methods Cytogenomic DNA copy number microarray $\left(\right.$ OncoScan $\left.{ }^{\circledR}\right)$ was performed on 18 cases of gliosarcoma. MetaCore ${ }^{\mathrm{TM}}$ enrichment was applied to the array results to detect associated molecular pathways.

Results The most frequent alteration was copy number loss, comprising 57\% of total copy number changes. The number of losses far exceeded the number of amplifications $(* * *,<0.001)$ and loss of heterozygosity events $(* * *,<0.001)$. Amplifications were infrequent (4.6\%), particularly for EGFR. Chromosomes 9 and 10 had the highest number of losses; a large portion of which correlated to $C D K N 2 A / B$ loss. Copy number gains were the second most common alteration (26.2\%), with the majority occurring on chromosome 7. MetaCore ${ }^{\mathrm{TM}}$ enrichment detected notable pathways for copy number gains including: HOXA, Rho family of GTPases, and EGFR; copy number loss including: WNT, NF-kß, and CDKN2A; and copy number loss of heterozygosity including: WNT and p53.

Conclusions The pathways and copy number alterations detected in this study may represent key drivers in gliosarcoma oncogenesis and may provide a starting point toward targeted oncologic analysis with therapeutic potential.
\end{abstract}

Keywords Gliosarcoma $\cdot$ Glioblastoma $\cdot$ Glioma $\cdot$ Oncoscan $\cdot$ Microarray $\cdot$ EGFR

$\begin{array}{ll}\text { Abbreviations } \\ \text { GBM } & \text { Glioblastoma } \\ \text { GFAP } & \text { Glial fibrillary acid protein } \\ \text { EGFR } & \text { Epidermal growth factor receptor } \\ \text { FFPE } & \text { Formalin fixed paraffin embedded } \\ \text { H\&E } & \text { Hematoxylin \& eosin } \\ \text { ChAS } & \text { Chromosome analysis suite } \\ \text { LOH } & \text { Loss of heterozygosity } \\ \text { Hmz } & \text { Homozygous (LOH) } \\ \text { WC } & \text { Whole chromosome } \\ \text { TCGA } & \text { The Cancer Genome Atlas }\end{array}$

Jennifer Hauenstein and Ashley Woods have contributed equally to this work.

Lindsey Lowder

lolowde@emory.edu; lindseyoga@gmail.com

Extended author information available on the last page of the article

\section{Introduction}

Glioblastoma (GBM) is the most aggressive primary malignant adult central nervous system tumor [1, 2]. Gliosarcoma, a histologic variant, accounts for $2 \%$ of all GBMs. Overall survival of gliosarcoma is similar to GBM except that systemic metastasis and skull invasion have been reported more frequently in gliosarcoma [3]. However, gliosarcoma exhibits several unique morphologic, immunohistochemical and molecular characteristics. Gliosarcoma is defined histologically as having biphasic neoplastic components; displaying both mesenchymal (fibroblastic, osseous, muscle or adipose differentiation) and glial differentiation [2]. The genomic alterations implicated in the malignant transformation of astrocytes are diverse, of which, IDH, TERT, EGFR, CDKN2A, TP53, PTEN, PDG$F R A$ and NFKBIA are the most commonly reported [3, 4]. These genes are involved in oxidative decarboxylation, maintenance of telomeres, stimulating protein tyrosine kinase, tumor 
suppression, cell signaling and a variety of other cellular processes. Gain of $7 \mathrm{p}$ in combination with $10 \mathrm{q}$ loss is associated with EGFR amplification and is a frequent finding in $I D H$ wildtype GBM. Of GBMs with EGFR protein overexpression, 70-90\% demonstrate EGFR gene amplification. Other mutations such as the EGFRvIII and missense mutations involving the extracellular domain are distinct from $E G F R$ mutations in non-glial cancers [5]. Interestingly, EGFR alterations vary amongst GBM subtypes, being rare in IDH-mutated GBM, and more prevalent in $I D H$-wildtype GBM [6]. Similar to $I D H$-wildtype GBM, gliosarcomas contain PTEN, CDKN2A and TP53 alterations, but amplification of the EGFR (epidermal growth factor receptor) are uncommon (4-8\%) [7-9]. Furthermore, the type of EGFR alterations reported in gliosarcoma are not usually seen in GBM; particularly EGFR point mutations have been detected in gliosarcomas (c.1831G $>$ A) [10]. Amplification of EGFR is present in 35-45\% of $I D H-$ wildtype GBMs [2]. Of the detected EGFR amplifications in gliosarcoma, it is speculated that these results are derived from the glial component of the tumor rather than the sarcomatous component. Immunohistochemistry supports this, staining for EGFR is negative in the sarcomatous component and positive in the glial component [11]. Gains of chromosome 7 without $E G F R$ amplification is frequent in gliosarcoma [9], leading one to believe the oncogenic driver for gliosarcomas may reside on chromosome 7 , but not necessarily related to the EGFR pathway. The myriad of known candidate genes located on chromosome 7 (CDK6, PDGF-A, $c-M E T$ ) may support this theory.

Given its poor prognosis, more research has been directed toward identifying specific mutations for targeted treatment of GBM. Several novel agents have been introduced that specifically target EGFR, but treatment with TKI's and EGFR antibodies have not yielded successful clinical results. The hypothesis is that TKI's work best for exon 19 and 21 mutations, which have not been detected in GBM [12]. The poor response of EGFR-targeted therapies raises the question of whether EGFR alterations truly represent key drivers in the genesis of glioblastomas. Therefore, we applied a wholegenome approach using the OncoScan ${ }^{\circledR}$ Assay to examine DNA copy number alterations, and identify any chromosome regions known to harbor oncogenic drivers.

\section{Materials and methods}

\section{Tissue processing, histopathology and clinical history review}

All tissue samples were obtained for diagnostic and research (under IRB approval) purposes at the time of surgical resection. A retrospective search within the institutional pathology database for "gliosarcoma" yielded 18 cases from which a OncoScan ${ }^{\circledR}$ was performed. Tissue processing consisted of fixation in $10 \%$ neutral buffered formalin and paraffin embedding (FFPE: formalin fixed paraffin embedded). Histopathologic tumor classification was rendered by multiple neuropathologists. Immunohistochemistry was performed following the manufacturers protocols using the Leica Bond Maxx III automated system for all primary antibodies: IDH1 (1:80, Dianova, Hamburg, Germany), GFAP (prediluted by manufacturer, DAKO, Carpinteria, CA). Positive and negative controls were stained alongside study materials.

Clinical data was retrieved from institutional electronic medical records and included: patient demographics, presenting symptoms, imaging characteristics, date of surgery, diagnosis, treatment, time to recurrence, length of follow-up, date of death. Less common IDHI and IDH2 mutations were previously tested for clinical purposes using Emory University Hospital "SNaPshot" mutation panel, the results of which were reviewed for each case.

\section{Copy number (CN)/single nucleotide polymorphism (SNP) microarray analysis}

For 17 specimens, formalin-fixed paraffin embedded (FFPE) brain tumor tissue was obtained and processed on Thermo Fisher's Oncoscan SNP DNA microarray. DNA was isolated using the QIAmp DNA FFPE Tissue kit. For quantification, DNA (80 ng) was prepared with the Qubit dsDNA Broad Range assay and detected with the Qubit Fluorometer 2.0. The assay was performed according to the manufacturer's protocol using a standard gel electrophoresis system or the Lonza FlashGel System for DNA size assessments. The assay consisted of overnight annealing of approximately 240,000 molecular inversion copy number probes and 74 somatic mutation probes, single nucleotide integration for SNP detection, two rounds of PCR, HAEIII digestion, and overnight hybridization of the libraries to the arrays. For one case, fresh tumor tissue was processed on Thermo Fisher's CytoScan HD SNP DNA microarray. DNA was isolated with the Qiagen QIAamp DNA mini kit with the Qiagen DNA Purification from Tissues protocol. The Nanodrop ND-2000 Spectrophotometer was used to quantify the DNA (250 ng). The assay was performed according to the manufacturer's protocol. The arrays were scanned and CEL files were processed in Thermo Fisher's Chromosome Analysis Suite (ChAS) software: NA33 workflow and hg19 genome Refs. [13-18]. 


\section{Radiographic imaging}

MRI images were manually inspected to characterize tumors according to criteria determined by the VASARI feature set [19] including: location, type of enhancement, margin definition, presence of hemorrhage or cysts, and invasion of adjacent structures such as the ependymal surfaces, pia, and cortex. The size of the T2 non-enhancing region, the $\mathrm{T} 1$ postcontrast enhancing region, and any areas of necrosis were recorded. Preoperative imaging (from our institution) on a comparable set of imaging from GBM patients $(n=20)$ from a similar time period (October 2014 and September 2015) was inspected using the same technique. Quantitative values, including measurements, were statistically compared using a two-sided $t$ test assuming equal variance. Proportions between groups were compared using a Fischer exact test.

\section{Statistics, pathway analysis, literature review}

The genes within CNV regions were obtained by using BEDTools (v2.26.0) intersect that overlapped hg19 human reference genome and CNV regions. Kaplan-Meier Survival curves were created using CASAS tool [20]. DNA copy number results were analyzed using MetaCore ${ }^{\mathrm{TM}}$ to generate molecular maps/pathways (confined to $\mathrm{p}<0.05$ for gains, losses, and LOH). Amplification events were too low in number to generate statistically significant ontology data. Literature review was attained via a Scopus ${ }^{\circledR}$ search for the keywords "gliosarcoma and EGFR," from 1 January 1995 to 31 July 2018.

\section{Results}

\section{Clinical characteristics, radiographic features and histopathology}

The cohort included 18 specimens (17 patients; 2 specimens were from the same patient) with a diagnosis of gliosarcoma. Twelve patients were male (70.6\%), and 5 patients were female $(29.4 \%)$ with a male to female ratio of $2.4: 1$. The median age at diagnosis was 61 years, with a range of 33-75 years. The median survival (Fig. 1) was 313 days (10.3 months) compared to 9 months (range 3-44 months) for a similar cohort of $20 I D H$-wildtype GBM cases from our database (resected between 2014 and 2015) [21].

Fifteen (15) patients had preoperative imaging available for review (Fig. 2). Gliosarcomas typically presented as aggressive appearing masses with extensive edema (diameter $84 \mathrm{~mm}$ ), marked enhancement (100\%), solid or thick enhancement (87\%), cortical involvement (87\%), pial invasion (53\%), and ependymal invasion (40\%). All had low or mixed average diffusion coefficient values (100\%). These findings were compared to a control cohort of 20 $I D H$-wildtype GBM cases (from our institution) taken from patient's who underwent surgical resection or biopsy between October 2014 and September 2015. The only distinct feature of gliosarcomas (compared to GBM) was a slightly larger area of edema ( 84 vs. $71 \mathrm{~mm}, \mathrm{p}=0.03$ for a comparable size enhancing mass ( 48 vs. $43 \mathrm{~mm}, \mathrm{p}=0.26$ ). Gliosarcomas were less likely to involve the occipital lobe $(6 \%$ vs. $35 \%, p=0.1)$ and have a thin rim of enhancement ( $13 \%$ vs. $40 \%, \mathrm{p}=0.13$ ). Both GBM and gliosarcomas invaded adjacent structures including the cerebral cortex, ependymal surfaces, and pia, although only one (1) gliosarcoma had invasion of the adjacent calvarium, a feature which was not seen in the glioblastoma set.

All cases were diagnosed as gliosarcoma, the glial component of which, exhibited confirmatory GFAP immunohistochemical positivity. A sarcomatous morphology was present in all 18 cases, but in 3 cases the mesenchymal portion consisted of adipocytic differentiation, osteoid differentiation, and myxoid/metaplastic morphology. All cases were IDH-negative in both the glial and sarcomatous components by immunohistochemistry and $I D H$-wildtype by molecular testing. The approximate proportion of sarcomatous components in each case ranged from 10 to $60 \%$.

\section{DNA copy number microarray analysis}

Total copy number abnormalities including amplification, loss of heterozygosity, gains, and losses for 18 gliosarcoma specimens was 305 (Table 1). Per specimen, the copy number changes ranged from 6 to 52 (median $=13$ ). Amplifications were infrequent (4.6\%); were present in 6 cases and included regions on: chromosome 3p, 7q, 9p, 12q, 4q, and $7 \mathrm{p}$. One case exhibited amplification of EGFR (7p11.2). However, gain of EGFR occurred in 13 cases (72\%) (Fig. 3). The most frequent type of copy number alteration was loss $(n=175)$, comprising $57 \%$ of the total copy number changes. The number of losses far exceeded the number of amplifications $(* * *,<0.001)$ and loss of heterozygosity events $(* * *$, $<0.001)$. Chromosomes 9 and 10 had the highest number of losses. Particularly, chromosome 10 harbored 13 (33\%) of whole chromosome losses. A large number of losses were from chromosome $9(\mathrm{n}=17)$, mostly correlating to loss of $C D K N 2 A / B$ (Table 1, Fig. 3). DNA copy number gains were the second most common change, totaling 80 events (26.2\%). The majority of gains occurred on chromosome 7 , which harbored 20 total gain events. Copy neutral loss of heterozygosity $(\mathrm{LOH})$ events were infrequent, consisting of 39 events. Chromosome 17 exhibited the highest number of LOH (Table 2) in the gliosarcoma cohort. One case exhibited tetraploidy, but all other cases were referenced in diploid. 


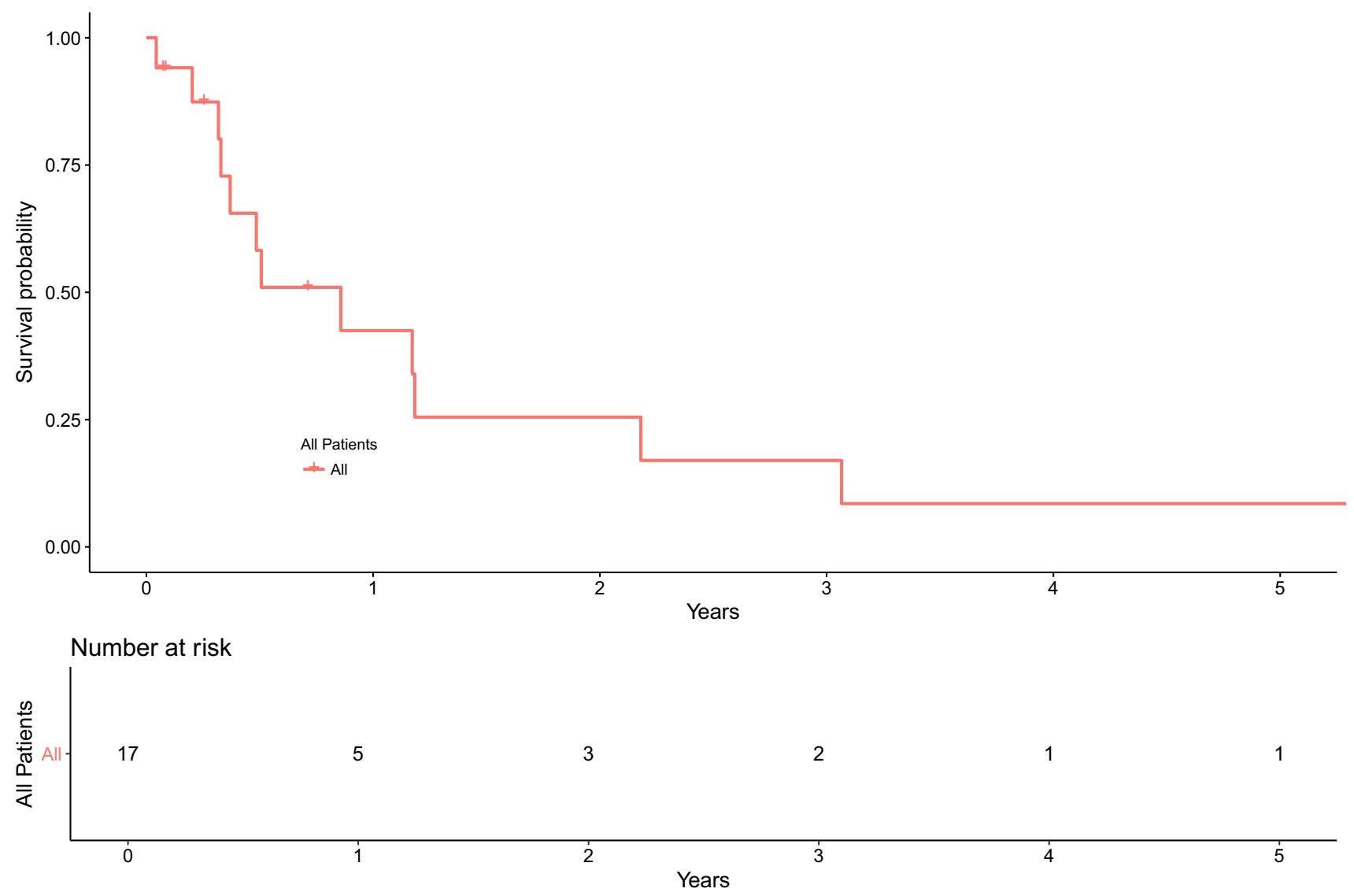

Fig. 1 Kaplan Meier survival curves for 17 patients with gliosarcoma. The median survival was 0.9 years (313 days) (95\% CI 0.3 , 2.2) versus 9 months for a similar cohort of $20 \mathrm{IDH}$-wildtype GBM

\section{Pathway enrichment (MetaCore ${ }^{\mathrm{TM}}$ )}

Pathways associated with copy number loss (Table 3 ) in the gliosarcoma cohort included WNT signaling, NF-kß, and CDKN2A. Several regions that showed chromosome loss were areas that code for WNT pathway proteins (Tcf (Lef), WNT, Sirtuin1, beta-TrCP, BMI-1, TCF7L2 (TCF4), DKK1). In addition, pathway enrichment revealed copy number loss in areas coding for components of the OX40L/ OX40 pathway (NF-kB2 (p52), IKK-alpha, NF-kB2 (p100), Calcineurin A (catalytic), PKC-theta, Perforin, NF-kB). Copy number loss of the regions containing CDKN2A/ p16INK4 (9p21) was present in several pathway maps. The NF-kß protein complex was also repeatedly represented.

Pathways associated with copy number gains included HOXA, EGFR, actin, adenylate cyclase, PKA-reg, IBP3, cytochrome c, Rac1, G-protein alpha-12 family, F-actin cytoskeleton, MRLC, IL-6. Gain of EGFR occurred in 13 of 18 cases $(72 \%)$. Gain of regions that code for adenylate cyclase, MRLC (myosin regulatory light chains) and PKAreg were frequent and routed to pathway maps related to cases (9 months). Bottom graphic: number of patient's surviving (considered to be "at risk") after each time period

myogenesis, and regulation of smooth muscle tone. The pathways with the highest statistical significance involved gains of areas containing HOXA genes, specifically centered around demethylation and methylation of histone $\mathrm{H} 3$ at lysine 27 (H3K27), and their role in stem cell differentiation. Rac1, a key member of the Rho family of GTPases, was a frequently identified network object related to pathways including cytoskeletal remodeling through kinase effectors of Rho GTPases. Chromosomal gains in the region coding for cytochrome $\mathrm{c}$ was also present, and linked to multiple maps related to apoptosis regulation and cell survival. IL-6 was frequently represented as a network object for copy number gains [22, 23].

Pathways associated with copy number loss of heterozygosity (LOH) included p53, ephrin-B, PLD2, PI3K, MEK4, CRK, and Dsh. Chromosome 17 exhibited the highest number of LOH events. This included the region encoding p53 (17p13.1), and mapped to pathways citing inhibiting of apoptosis. Interestingly, there was also WNT pathway involvement through LOH of Dsh (Dishevelled), PLD2, MEK4, and CRK; mapping to canonical WNT signaling in 

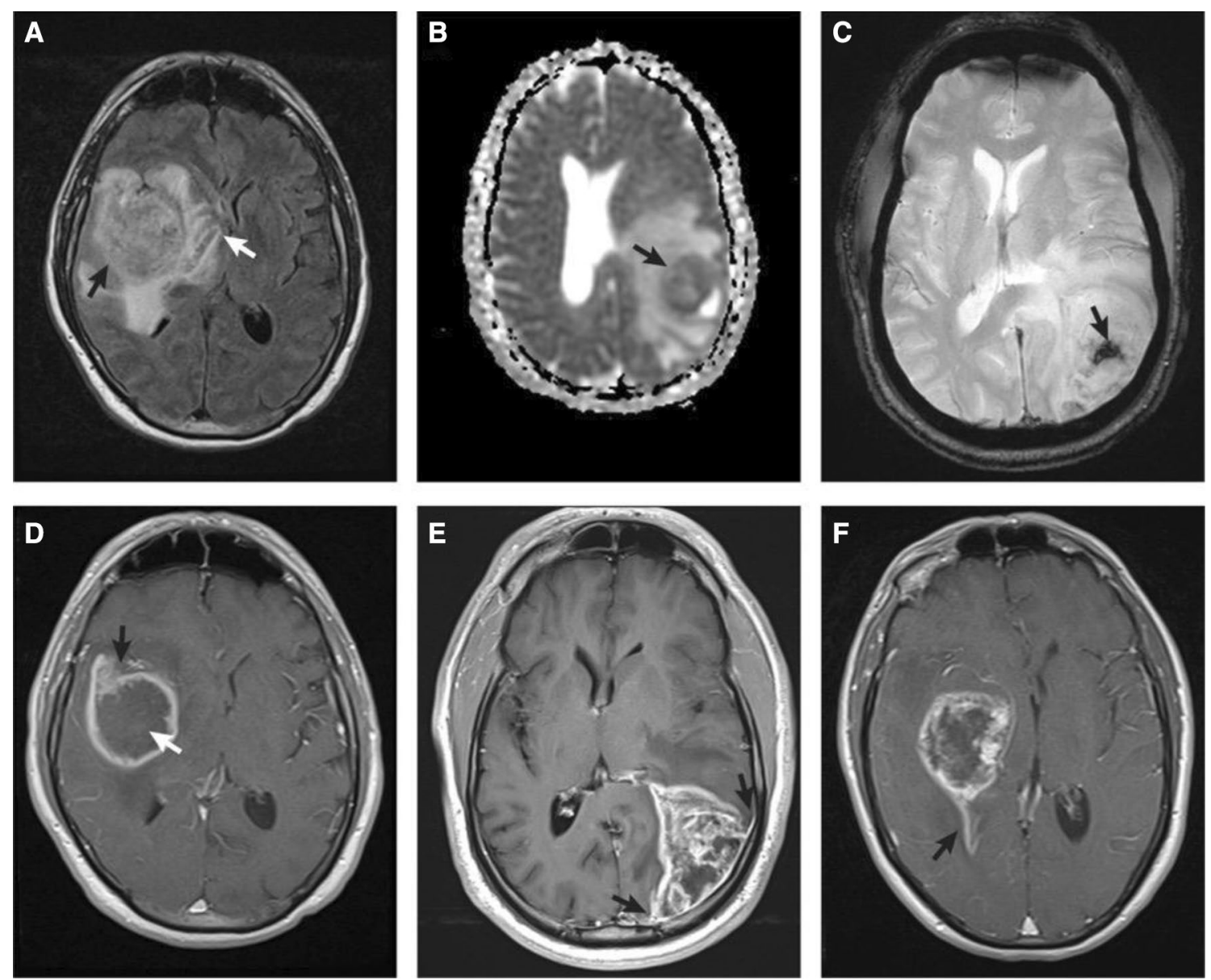

Fig. 2 Typical MRI features of gliosarcomas. a FLAIR image demonstrating a centrally isointense mass (black arrow) with extensive surrounding edema extending into the basal ganglia (white arrow). b ADC image showing low diffusion values in the central enhancing portion of the mass (black arrow). c GRE image demonstrating cen-

colorectal cancer, hepatocellular cancer, and lung cancer; frequently in the same maps associated with $\mathrm{p} 53$. $\mathrm{LOH}$ of regions encoding for several proteins related to angiogenesis was present (ephrin-B, PDF, TWEAK).

\section{Comparison to published data}

A Scopus ${ }^{\circledR}$ search for "gliosarcoma and $E G F R$," from 1 January 1995 to 31 July 2018 yielded 58 articles, 9 of which included EGFR testing (Table 3). Actor et al. analyzed the largest number of cases $(\mathrm{n}=38)$ and detected 3 gliosarcoma cases with EGFR amplification using a combination of comparative genomic hybridization, single-strand conformation polymorphism/heteroduplex analysis, duplex PCR, and southern blot analysis. Three (3) studies [24-26] used florescent in situ hybridization (FISH) to detect amplification of EGFR. Two (2) studies used next-generation sequencing tral areas of susceptibility compatible with internal hemorrhage. $\mathbf{d}-\mathbf{f}$ Postcontrast T1-weighted images showing a thick rim of enhancement (d black arrow) with central necrosis (d white arrow), pial invasion (e black arrows), and ependymal invasion (f black arrow)

(NGS), which detected EGFR mutations, c. $1831 \mathrm{G}>\mathrm{A}$ and G719D [10, 27]. Although EGFR immunohistochemistry was performed in 2 studies [11, 28], the ability of immunohistochemistry to differentiated $E G F R$ gain from amplification is uncertain. OncoScan ${ }^{\circledR}$ (DNA copy number analysis) was not performed in any of the 9 articles reviewed.

\section{Discussion}

Overall, our data showed that DNA copy number losses were frequent and amplifications were infrequent in gliosarcoma. The majority of copy number loss occurred on chromosomes 9 and 10; localizing to regions containing $C D K N 2 A$ and $C D K N 2 B$ genes. The $C D K N 2 A$ gene encodes for proteins p16 and p14arf, tumor suppressors that regulate the p53 and RB1 cell cycle [29]. The $C D K N 2 B$ gene 
Table 1 Molecular alterations in 18 gliosarcoma specimens (17 patients)

\begin{tabular}{|c|c|c|c|c|c|c|c|}
\hline Case & egfr status & Copy number abnormalities & Total CN Abn. & Amp & Gain & Loss & $\mathrm{LOH}$ \\
\hline S13-1 & Normal & 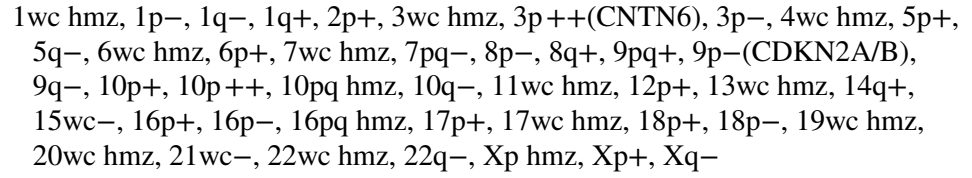 & 52 & 4 & 17 & 17 & 14 \\
\hline S14-1 & Gain & $\begin{array}{l}1 \mathrm{wc}-, 1 \mathrm{p}+, 2 \mathrm{wc}-, 6 \mathrm{pq} \text { cth }, 6 \mathrm{q}-, 7 \mathrm{wc}+, 7 \mathrm{q}++(\mathrm{MET}), 9 \mathrm{p}-, 9 \mathrm{p}++(\mathrm{CER} 1 \\
\text { TEK), } 9 \mathrm{p}-(\mathrm{CDKN} 2 \mathrm{~A} / \mathrm{B}), 9 \mathrm{p}+, 9 \mathrm{pq}-, 10 \mathrm{wc}-, 15 \mathrm{wc}-, 18 \mathrm{q}+, 18 \mathrm{q}++, 18 \mathrm{q}-\end{array}$ & 18 & 4 & 3 & 11 & 0 \\
\hline S14-2 & Gain & $\begin{array}{l}1 \mathrm{q}+, 2 \mathrm{p} \mathrm{hmz}, 3 \mathrm{p}-, 6 \mathrm{q}-, 6 \mathrm{q}+, 7 \mathrm{pq}+, 7 \mathrm{q}+, 9 \mathrm{p}-(\mathrm{CDKN} 2 \mathrm{~A}), 9 \mathrm{q}-, 10 \mathrm{wc}-, 11 \mathrm{q}- \\
17 \mathrm{q}-, 17 \mathrm{q}+, 19 \mathrm{q}+, 22 \mathrm{wc}-\end{array}$ & 21 & 0 & 7 & 13 & 1 \\
\hline S15-2 & Gain & $6 q-, 7 w c+, 9 p-(C D K N 2 A), 10 w c h m z, 17 q-, 22 w c-$ & 9 & 0 & 1 & 7 & 1 \\
\hline S15-3 & Gain & $1 \mathrm{p}-, 2 \mathrm{q}-, 3 \mathrm{p} \mathrm{hmz}, 4 \mathrm{q}-, 7 \mathrm{wc}+, 9 \mathrm{p}-(\mathrm{CDKN} 2 \mathrm{~A}), 10 \mathrm{wc}-, 13 \mathrm{q}-$ & 13 & 0 & 2 & 10 & 1 \\
\hline S15-4 & Normal & $\begin{array}{c}1 \mathrm{pq}+\mathrm{hmz}, 1 \mathrm{q}-, 2 \mathrm{wc}-\mathrm{hmz}, 3 \mathrm{wc}-, 6 \mathrm{q}-, 7 \mathrm{pq}+, 8 \mathrm{q}+, 9 \mathrm{wc}-, 10 \mathrm{wc}-, 11 \mathrm{wc}- \\
12 \mathrm{wc}-, 13 \mathrm{q}-, 16 \mathrm{wc}-, 17 \mathrm{wc}-, 18 \mathrm{wc}-, 19 \mathrm{wc}-, 20 \mathrm{wc}-, \text { Xwc- }\end{array}$ & 19 & 0 & 3 & 16 & 2 \\
\hline S16-3 & Normal & $\begin{array}{l}8 w c+, 9 p-(C D K N 2 A), 9 p q-, 10 w c-, 13 w c-, 14 w c-, 15 w c-, 17 w c h m z \\
18 w c-, 21 w c h m z\end{array}$ & 10 & 0 & 1 & 7 & 2 \\
\hline S16-4 & Gain & $7 \mathrm{wc}+, 9 \mathrm{p}-(\mathrm{CDKN} 2 \mathrm{~A}), 10 \mathrm{wc} \mathrm{hmz}, 12 \mathrm{q}-, 14 \mathrm{q}-, 15 \mathrm{q}-, 17 \mathrm{p} \mathrm{hmz}, 19 \mathrm{wc} \mathrm{hmz}$ & 9 & 0 & 1 & 5 & 3 \\
\hline S16-5 & Gain & $\begin{array}{l}3 \mathrm{q}-, 5 w c+, 7 p q+, 7 q \text { hmz }, 10 w c-, 11 q-, 12 q++(\text { CDK4; FRS2; MDM2), } \\
12 q-, 13 q-, 16 q-, 17 w c+, 19 q-\end{array}$ & 16 & 3 & 4 & 8 & 1 \\
\hline S16-6 & Amp & $\begin{array}{c}1 \mathrm{wc}+, 2 \mathrm{p}+, 3 \mathrm{p}+, 4 \mathrm{wc}+, 4 \mathrm{pq}-, 5 \mathrm{wc}+, 6 \mathrm{q}+, 7 \mathrm{pq}+, 7 \mathrm{wc}+, 7 \mathrm{p}++(\mathrm{EGFR}), 8 \mathrm{wc}+ \\
9 \mathrm{wc}+, 10 \mathrm{wc}-, 10 \mathrm{q}-(\mathrm{PTEN}), 13 \mathrm{q}+, 13 \mathrm{wc}-, 13 \mathrm{q}-(\mathrm{RB} 1), 14 \mathrm{q}+, 14 \mathrm{q} \mathrm{hmz} \\
15 \mathrm{wc}-, 15 \mathrm{q}-, 16 \mathrm{p}+, 16 \mathrm{pq}-, 17 \mathrm{wc} \text { hmz, 18pq-, 20wc+, 21wc+, } 22 \mathrm{wc}+\end{array}$ & 34 & 1 & 20 & 11 & 2 \\
\hline S17-1 & Gain & $\begin{array}{l}\text { This case was analyzed in reference to tetraploidy: } \\
6 \mathrm{q}-, 7 \mathrm{wc}+, 7 \mathrm{q}++(\mathrm{MET}), 8 \mathrm{p}-, 9 \mathrm{p}-(\mathrm{CDKN} 2 \mathrm{~A} / \mathrm{B}), 10 \mathrm{pq}-, 11 \mathrm{p}-, 12 \mathrm{q}-, 14 \mathrm{q}-\text {, } \\
16 \mathrm{p}-, 17 \mathrm{pq}--, 20 \mathrm{q}-, 22 \mathrm{wc}-\end{array}$ & 23 & 1 & 1 & 21 & 0 \\
\hline S17-2 & Gain & $\begin{array}{l}1 \mathrm{p}-(\mathrm{FAF} 1), 3 \mathrm{q}+, 6 \mathrm{p}-, 7 \mathrm{wc}+, 9 \mathrm{p}-(\mathrm{CDKN} 2 \mathrm{~A} / \mathrm{B}), 9 \mathrm{q}+, 10 \mathrm{wc}-, 10 \mathrm{q}-(\mathrm{PTEN}) \\
12 \mathrm{q}-, 14 \mathrm{wc}-, 17 \mathrm{p} \mathrm{hmz}\end{array}$ & 12 & 0 & 3 & 8 & 1 \\
\hline S17-4 & Gain & $2 \mathrm{q}-, 4 \mathrm{q}-, 7 \mathrm{pq}+, 9 \mathrm{p}-(\mathrm{CDKN} 2 \mathrm{~A} / \mathrm{B}), 10 \mathrm{wc}-, 11 \mathrm{q}-, 13 \mathrm{wc}-, 15 \mathrm{q}-, 17 \mathrm{q}-$ & 13 & 0 & 4 & 9 & 0 \\
\hline S18-1 & Gain & $\begin{array}{l}2 \mathrm{wc} \mathrm{hmz}, 2 \mathrm{p}-, 3 \mathrm{p} \mathrm{hmz}, 3 \mathrm{pq}+, 5 \mathrm{wc} \mathrm{hmz}, 6 \mathrm{wc} \mathrm{hmz}, 7 \mathrm{wc}+, 8 \mathrm{p}-, 8 \mathrm{pq} \mathrm{hmz}, 9 \mathrm{pq}+ \\
9 \mathrm{p} \mathrm{hmz}, 9 \mathrm{p}-(\mathrm{CDKN} 2 \mathrm{~A}), 10 \mathrm{wc}-, 12 \mathrm{wc}+, 15 \mathrm{wc}+, 16 \mathrm{wc}+, 17 \mathrm{pq}-, 17 \mathrm{q}+\mathrm{hmz} \\
18 \mathrm{wc} \text { hmz, } 19 \mathrm{wc} \text { hmz, 20wc+, 20q-, 21q hmz }\end{array}$ & 25 & 0 & 9 & 7 & 10 \\
\hline S18-2 & Normal & $3 q+, 3 q-, 6 p-, 10 p q-, 13 q-, 14 q-, 22 w c-$ & 10 & 0 & 1 & 9 & 0 \\
\hline S18-3 & Gain & $2 p-, 7 w c+, 9 p-(C D K N 2 A / B), 10 w c-, 15 q-, 17 w c h m z, 20 q-$ & 8 & 0 & 1 & 6 & 1 \\
\hline $\mathrm{S} 18-4$ & Gain & $\begin{array}{l}4 \mathrm{q}++(\mathrm{CHIC} 2, \text { PDGFRA, KIT, KDR }), 7 w c+, 9 \mathrm{p}-(\mathrm{CDKN} 2 \mathrm{~A}), 10 \mathrm{wc}-, 15 \mathrm{q}- \\
17 \mathrm{q}-\end{array}$ & 7 & 1 & 1 & 5 & 0 \\
\hline S18-5 & Gain & $7 \mathrm{wc}+, 8 \mathrm{q}-, 9 \mathrm{p}-(\mathrm{CDKN} 2 \mathrm{~A} / \mathrm{B}), 10 \mathrm{wc}-$ & 6 & 0 & 1 & 5 & 0 \\
\hline Total & & & 305 & 14 & 80 & 175 & 39 \\
\hline
\end{tabular}

Summary of copy number alterations including EGFR status for 18 cases of gliosarcoma. + gain, ++ amplification, - loss, - homozygous loss, $W C$ whole chromosome, $H M Z$ loss of heterozygosity, $C T H$ chromothripsis. Manually summarized: If multiple regions of gain, loss, or amp on a chromosome, it was only represented 1 time. If it was less than whole chromosome, then pq designation. Only focal abnormalities with gene names represented

encodes for the $\mathrm{p} 15^{\text {ink } 4 \mathrm{~b}}$ protein, a member of the $\mathrm{p} 16^{\text {ink4 }}$ $(C D K N 2 A)$ family, and a cell growth regulator that inhibits G1 progression [30]. Homozygous loss of $C D K N 2 A$ is common in GBM (35-50\% [2]) and loss of this locus occurred in 14 of 18 gliosarcoma specimens [31]. Other potential pathways involved in gliosarcoma include activation of the OX40L/OX40 pathway, which has been shown to induce strong immunity and antitumor effects in GBM [32]. DNA copy number loss was present in areas coding for several protein components of the OX40L/OX40 pathway (NF-kB2 (p52), IKK-alpha, NF-kB2 (p100), Calcineurin A (catalytic), PKC-theta, Perforin, NF-kB). Conversely, several regions that showed chromosome loss were areas that coded for WNT pathway proteins (Tcf (Lef), WNT, Sirtuin1, beta-TrCP, BMI-1, TCF7L2 (TCF4), DKK1). In the activated or overexpressed state, most of these WNT pathway proteins (with the exception of DKK1) promote cell proliferation and cell survival [33]. However, DKK1 (Dickkopf-1) is considered to be a negative regulator of WNT pathway, and has been implicated as a candidate gene that is epigenetically silenced in medulloblastoma [34], loss of which, may provide an avenue for WNT pathway activation with subsequent cell proliferation and survival. One study showed that DKK1 expression led to glioma cell sensitivity 


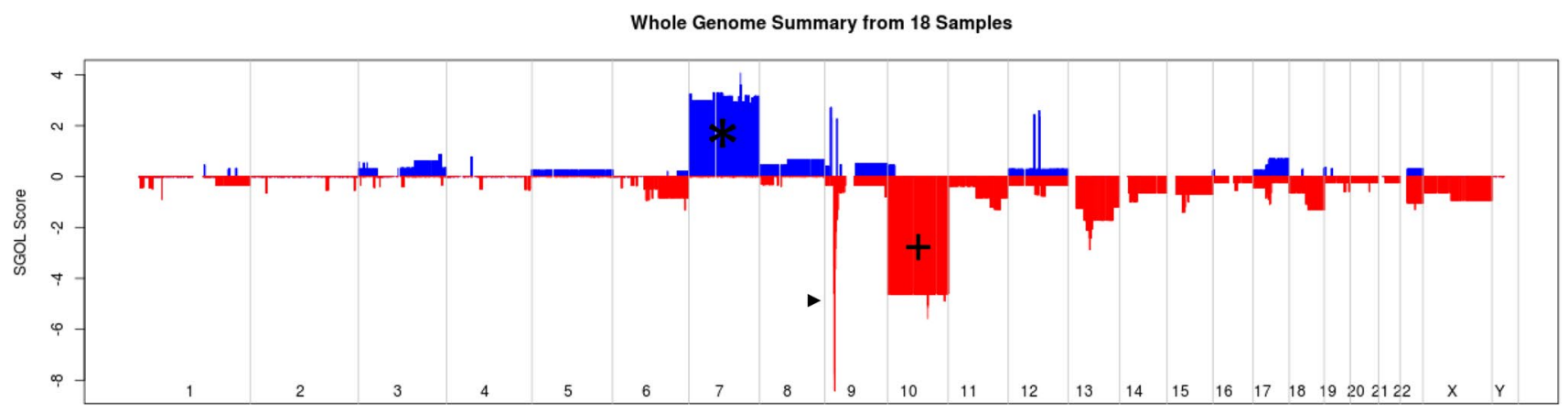

Whole Genome Summary from 580 Samples

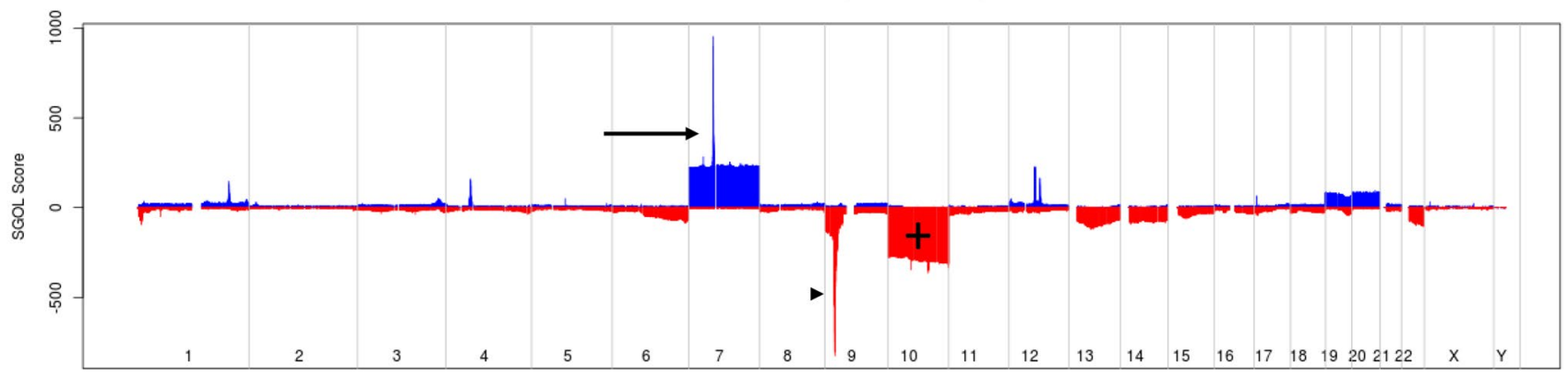

Fig. 3 Whole genome view illustrating Oncoscan (CN/SNP DNA microarray) results. 18 gliosarcoma specimens (top) and 580 glioblastoma cases (bottom, taken from the TCGA). Focal amplification of EGFR (7p11.2) is evident in the GBM TCGA dataset (arrow), but gains of chromosome $7(*)$ without EGFR (7p11.2) amplification are present in the gliosarcoma cases. Loss of chromosome 10
(+) and loss of 9p containing $C D K N 2 A / B$ (arrowheads) are present in both GBM and gliosarcoma (+). $\mathrm{X}$ axis: each chromosome. $\mathrm{Y}$ axis: SGOL score, which represents segments of gains (blue) and losses (red) across chromosomes. Both graphics created with Copy Number Explorer. https://arraycgh.shinyapps.io/Copy_Number_Explorer/ [52]. Data from bottom graphic provided by GBM TCGA Dec 2014 to chemotherapy-induced apoptosis [35]. Another protein with repetitive representation after pathway enrichment was $\mathrm{NF}-\mathrm{k} \beta$, a protein complex that controls DNA transcription, but can induce cell proliferation and anti-apoptosis if misregulated or constitutively activated. Aberrant activation of $\mathrm{NF}-\mathrm{k} \beta$ in glioblastoma, leading to cell invasive capabilities, resistance to radiotherapy, and even promotion of mesenchymal phenotype has been reported [36]. Studies to evaluate the therapeutic effect of inhibition of NF-kß, based on these mechanisms have been published [37]. However, due to the multifactorial role NF-kß plays in a diverse number of biological processes (cell proliferation, survival, motility, DNA repair, inflammation), a direct pathway to neoplasia in GBM is unclear. Our data shows that there is copy number loss in the region encoding for $\mathrm{NF}-\mathrm{k} \beta$ in gliosarcoma, implying that activation of the NF-kß pathway does not play a role in gliosarcoma genesis. However, it is possible that loss of $\mathrm{NF}-\mathrm{k} \beta$ could lead to loss of DNA repair mechanisms, resulting in neoplasia.

Chromosome gains were the second most common copy number abnormality. Gains in regions coding for signaling molecules known to promote cell proliferation (F-actin cytoskeleton, actin cytoskeletal) and cytoskeleton remodeling (G-protein alpha-12 family, F-actin cytoskeleton) were present [38]. Interestingly, the Rho GTPase family, including rac1has been implicated in the modulation of glioma cell migration through cytoskeletal rearrangement [39]. Homeobox (HOX) genes are responsible for regulation of transcription factors during embryonic development, the differential expression of which, have been tied to many different cancers, including glioblastoma [40]. Specifically, high expression of HOXA9 and HOXA10 have been reported in human glioma cell lines [40]. The expression of HOXA13 has been proposed as an activator of WNT and TGF-B-induced epithelial to mesenchymal transition in glioma progression [41]. Resistance to radiation and chemotherapy through the activation of HOXA, thereby inducing increased proliferation and decreased apoptosis in cultured glioblastoma cells has also been reported [42]. Our microarray data showed gains in the regions encoding HOXA1, HOXA3, HOXA7, HOXA11, and HOXA13. Interestingly, several studies have demonstrated overexpression of HOX genes in Ewing sarcoma [43, 44] and undifferentiated small round blue cell sarcoma [45]; perhaps raising the question of whether HOX genes play a role in mesenchymal phenotype in gliosarcoma.

Copy neutral loss of heterozygosity $(\mathrm{LOH})$ events were less frequent. OncoScan ${ }^{\mathrm{TM}}$ detected loss of the region 
Table 2 Reported EGFR alterations in gliosarcoma

\begin{tabular}{|c|c|c|c|c|}
\hline References $^{\mathrm{a}}$ & $\begin{array}{l}\text { Number of cases } \\
\text { analyzed for } E G F R \\
\text { status }\end{array}$ & Methodology & $E G F R$ status & Clinical outcome $^{c}$ \\
\hline Reis et al. [9] & 19 & $\begin{array}{l}\text { Differential PCR, Immunohisto- } \\
\text { chemistry }\end{array}$ & No alterations $(0 / 19)$ & Not available \\
\hline Actor et al. [11] & 38 & $\begin{array}{l}\text { Comparative genomic hybridiza- } \\
\text { tion, Single-strand conforma- } \\
\text { tion polymorphism/heterodu- } \\
\text { plex analysis, Duplex PCR, } \\
\text { Southern blot analysis }\end{array}$ & $\begin{array}{l}\text { Amplification }(3 / 38) \\
\text { Strong + IHC }(2 / 38)^{d}\end{array}$ & Not available \\
\hline $\begin{array}{l}\text { Kleinschmidt- } \\
\text { DeMasters } \\
\text { et al. [24] }\end{array}$ & 1 & FISH & No amplification $(0 / 1)$ & Overall survival (OS): 34 weeks \\
\hline Lin et al. [28] & 7 & Immunohistochemistry & Strong $+\mathrm{IHC}(3 / 7)^{\mathrm{e}}$ & $\begin{array}{l}\text { Median progression free survival } \\
\text { (PFS): 0-1+ (EGFR IHC Score): } \\
17.2 \text { months } \\
\text { 2-3+ (EGFR IHC Score): } \\
\text { 11.2 months } \\
\text { Median Overall Survival (OS): } \\
0-1+(\text { EGFR IHC Score): } \\
\text { 20.4 months } \\
\text { 2-3+ (EGFR IHC Score): } \\
\text { 17.7 months }\end{array}$ \\
\hline Yao et al. [25] & 1 & FISH & No amplification $(0 / 1)$ & Not available \\
\hline Cachia et al. [10] & 14 & $\begin{array}{l}\text { PCR-based primer exten- } \\
\text { sion assay, Next Generation } \\
\text { sequencing, Targeted gene } \\
\text { whole exome DNA sequencing, } \\
\text { Immunohistochemistry }\end{array}$ & c. $1831 \mathrm{G}>\mathrm{A}(1 / 19)$ & $\begin{array}{l}\text { Case \#4 outcome data not denoted, } \\
\text { not able to separate } E G F R \text { from } \\
\text { WT }\end{array}$ \\
\hline Shelly et al. [26] & 31 & FISH & Amplification (1/31) & $\begin{array}{l}\text { Outcome data not stratified by } \\
\text { histology }\end{array}$ \\
\hline Pain et al. [27] & 1 & $\begin{array}{l}\text { Next generation DNA sequenc- } \\
\text { ing, CISH }\end{array}$ & EGFR G719D mutation (1/1) & Not available \\
\hline Smith et al. [53] & 16 & Not available & $\begin{array}{l}\text { No amplification }(0 / 9) \\
\text { No EGFRvIII mutation }(0 / 7)\end{array}$ & $\begin{array}{l}\text { Outcome data available, not strati- } \\
\text { fied by EGFR status }\end{array}$ \\
\hline
\end{tabular}

Summary of a literature review derived from a Scopus® search for the keywords "gliosarcoma and EGFR," from 1 January 1995 to 31 July 2018 $E G F R$ epidermal growth factor receptor, $P C R$ polymerase chain reaction, IHC immunohistochemistry, WT wild type, FISH Fluorescence in situ hybridization, $C I S H$ chromogenic in situ hybridization

${ }^{a}$ Refer to bibliography for full citation

${ }^{\mathrm{b}}$ The methodology used to detect EGFR alterations

${ }^{c}$ Overall survival of cases with $E G F R$ alteration versus wildtype (WT)

${ }^{\mathrm{d}}$ Strong immunohistochemical staining (3+) was detected in the glial component only in 2 of the 3 cases with EGFR amplification

${ }^{\mathrm{e}}$ Strong immunohistochemical staining (3+) was detected in the sarcomatous component in 3 of 7 cases

encoding p53 (17p13.1), and while p53 alterations have been well documented in gliomas, some studies suggests that $\mathrm{LOH}$ of a single cell cycle regulator, such as p53 may be insufficient for development of gliomas [46]. In the context of this study, concurrent loss of p16 with LOH of p53 may play a large role in the genesis of gliosarcoma. Another pathway that was well represented across $\mathrm{LOH}$, gains and losses after MetaCore ${ }^{\mathrm{TM}}$ enrichment was chemotaxis lysophosphatidic acid signaling. Lysophosphatidic acid (LPA) is a phospholipid that binds to G protein-coupled receptors (GPCRs) leading to chemotaxis, cell proliferation, cell growth and cell survival through a complex network of signaling cascades [38]. LPA was shown to be increased in GBM stem cells from the subventricular zone via LPA/Rho signaling cascades and proposed as a mechanism for GBM invasion and angiogenesis, a possible therapeutic target using LPAR antagonist and LPA synthesis inhibitors [47, 48]. Another region with copy neutral $\mathrm{LOH}$ encoded for the network object Ephrin-B, a protein ligand known to promote angiogenesis, as well as in developmental processes such as axon guidance, cell migration, and maturation of cortical dendrites. The Eph receptor tyrosine kinases and ephrin ligands 
Table 3 MetaCore ${ }^{\mathrm{TM}}$ pathway enrichment. Summary of proteins ("Network objects") implicated in chromosome regions of DNA copy number gain, loss, and LOH in 18 gliosarcoma cases (17 patients)

\begin{tabular}{lll}
\hline DNA copy number type (gain, loss, LOH) & \\
\hline Gain & Loss & LOH \\
\hline HOXA & WNT & p53 \\
EGFR & p16INK4/CDKN2A & Ephrin-B \\
Actin & NF- k3 & PLD2 \\
Adenylate cyclase & DKK1 & PI3 K \\
PKA-reg & PTEN & MEK4 \\
IBP3 & IKK-alpha & CRK \\
Cytochrome C & Calcineurin A & Dsh \\
Rac1 & MGMT & \\
G-protein alpha-12 family & PKC-theta & \\
F-actin cytoskeleton & p14ARF & \\
Cytochrome C & & \\
MRLC & & \\
IL-6 & & \\
\hline
\end{tabular}

have been implicated in both the inhibition and promotion of neoplasia and may play a key role in glioma genesis [49].

Epidermal growth factor receptor $(E G F R)$ is mutated or amplified in 35-45\% of $I D H$-wildtype glioblastomas [2] and implicated as a key driver [50]. Gliosarcoma, however, does not exhibit amplification or mutations of EGFR at the same frequency, suggesting there may be additional/alternate mechanisms propelling tumorigenesis and potentially mesenchymal transition into a sarcoma phenotype. Our data supports other studies that show a very low prevalence of $E G F R$ amplification in gliosarcoma, but did show frequent gain of chromosome 7 (72\%) containing EGFR locus. It is important to note that amplification or mutation of EGFR is not necessarily required for EGFR activation. For example, copy number gain of SYNJ2 in breast cancer leads to EGFR activation by altered trafficking pathways [50]. Therefore, even though EGFR amplification is not common in gliosarcoma, EGFR pathway activation may still be present. Gain as oppose to amplification of EGFR may be sufficient for EGFR pathway activation in of itself. In contrast, some believe copy number gain (as oppose to amplification) of EGFR reflects chromosomal instability in cancer cells and has no biological significance [51]. Thus, it is unclear whether EGFR pathway activation is present in gliosarcoma; perhaps it is present through indirect mechanisms and not necessarily through overexpression of EGFR due to gene amplification. Our study confirms that EGFR amplification is uncommon in gliosarcoma and provides whole-genome evidence of possible driver pathways from a DNA copy number perspective. Further analysis to pinpoint specific loci within the altered copy number regions is needed.
The strengths of this study are that it comprises the largest cohort of gliosarcoma cases with DNA copy number analysis by OncoScan ${ }^{\mathrm{TM}}$. However, there were a few limitations. We intended this to represent an initial overview of copy number changes in a large cohort of gliosarcoma cases, and did not include OncoScan ${ }^{\mathrm{TM}}$ data from GBM. In the future, it would be ideal to compare our gliosarcoma cohort to regional-matched GBM cases. Also, no general effort was made to separate sarcomatous from glioblastoma components for OncoScan ${ }^{\mathrm{TM}}$ analysis. An interesting next step would be to separate the glioblastoma from sarcoma components microscopically, and re-analyze the separate components.

\section{Conclusions}

Gliosarcoma, much like GBM, is a fatal diagnosis with no cure. We present a comprehensive whole-genome copy number analysis of gliosarcoma performed in an effort to identify chromosome regions that may represent plausible drivers for gliosarcoma genesis. This study may provide a starting point to direct more targeted oncologic analysis and discover genetic alterations that lead to pathways with therapeutic potential.

Acknowledgements Research reported in this publication was supported in part by the Biostatistics and Bioinformatics shared resource of Winship Cancer Institute of Emory University and NIH/NCI under Award Number P30CA138292. The content is solely the responsibility of the authors and does not necessarily represent the official views of the National Institutes of Health.

Author contributions LL, JH, DS, SN analyzed and interpreted the DNA microarray analysis. AW and LL provided the introduction. LL, $\mathrm{SN}$, MS performed the histological examination of the brain samples. HC performed the pathway enrichment. LL, HC, JK, SS performed the pathway interpretation. MR and JK determined survival characteristics. BW, SS and JO provided the clinical data including surgical and imaging characteristics. LL was the main contributor in writing the manuscript. All authors read and approved the final manuscript.

Funding Funding for data interpretation and analysis (Winship Cancer Institute Biostatistics and Bioinformatics Shared Resource) was provided by K08 award NS083626 (Principal investigator: Soma Sengupta, M.D., Ph.D.).

Data availability The datasets used and/or analysed during the current study available from the corresponding author on reasonable request.

\section{Compliance with ethical standards}

Competing interests The authors declare that they have no competing interests.

Consent for publication Consent for publication was provided by the Emory University Institutional Review Board (IRB, 1599 Clifton Road, 
NE, 5th floor, Atlanta, GA 30322 United States; IRB@emory.edu) under the Emory University Brain Tumor Sample and Information Resource (BTSIR; AM16 IRB00045732).

Ethics approval and consent to participate Ethics approval and consent to participate was provided by the Emory University Institutional Review Board (IRB, 1599 Clifton Road, NE, 5th floor, Atlanta, GA 30322 United States; IRB@emory.edu) under the Emory University Brain Tumor Sample and Information Resource (BTSIR; AM16 IRB00045732).

Open Access This article is distributed under the terms of the Creative Commons Attribution 4.0 International License (http://creativeco mmons.org/licenses/by/4.0/), which permits unrestricted use, distribution, and reproduction in any medium, provided you give appropriate credit to the original author(s) and the source, provide a link to the Creative Commons license, and indicate if changes were made.

\section{References}

1. Walid M (2008) Prognostic factors for long-term survival after glioblastoma. Perm J. https://doi.org/10.7812/tpp/08-027

2. International Agency for Research on Cancer (2016) WHO Classification of Tumours of the Central Nervous System (IARC WHO Classification of Tumours). http://publications.iarc.fr/ Book-And-Report-Series/Who-Iarc-Classification-Of-Tumours/ Who-Classification-Of-Tumours-Of-The-Central-Nervous-Syste m-2016\%0Ahttp://link.springer.com/10.1007/s00401-016-1545-1

3. Louis DN, Perry A, Reifenberger G, von Deimling A, FigarellaBranger D, Cavenee WK, Ohgaki H, Wiestler OD, Kleihues P, Ellison DW (2016) The 2016 World Health Organization classification of tumors of the central nervous system: a summary. Acta Neuropathol 131(2016):1-18. https://doi.org/10.1007/s0040 1-016-1545-1

4. Brennan CW, Verhaak RG, McKenna A, Campos B, Noushmehr H, Salama SR, Zheng S, Chakravarty D, Sanborn JZ, Berman SH, Beroukhim R (2014) The somatic genomic landscape of glioblastoma. Cell 157(3):753

5. Aldape K, Gelareh Z, Von Deimling A (2015) Glioblastoma: pathology, molecular mechanisms and markers. Acta Neuropathol 129:809-827. https://doi.org/10.1007/s00401-015-1424-1

6. Watanabe K, Tachibana O, Sata K, Yonekawa Y, Kleihues P, Ohgaki H (1996) Overexpression of the EGF receptor and p53 mutations are mutually exclusive in the evolution of primary and secondary glioblastomas. Brain Pathol 6:217-223. https://doi. org/10.1097/00005072-199605000-00017 discussion 23-4

7. Biernat W, Huang H, Yokoo H, Kleihues P, Ohgaki H (2004) Predominant expression of mutant EGFR (EGFRvIII) is rare in primary glioblastomas. Brain Pathol 14:131-136. https://doi. org/10.1111/j.1750-3639.2004.tb00045.x

8. Han SJ, Yang I, Tihan T, Prados MD, Parsa AT (2010) Primary gliosarcoma: key clinical and pathologic distinctions from glioblastoma with implications as a unique oncologic entity. J Neurooncol 96:313-320. https://doi.org/10.1007/s11060-009-9973-6

9. Reis RM, Konu-Lebleblicioglu D, Lopes JM, Kleihues P, Ohgaki $\mathrm{H}$ (2000) Genetic profile of gliosarcomas. Am J Pathol 178:24962503. https://doi.org/10.1016/j.ajpath.2011.02.031

10. Cachia D, Kamiya-Matsuoka C, Mandel JJ, Olar A, Cykowski MD, Armstrong TS, Fuller GN, Gilbert MR, De Groot JF (2015) Primary and secondary gliosarcomas: clinical, molecular and survival characteristics. J Neurooncol 125:401-410. https://doi. org/10.1007/s11060-015-1930-y
11. Actor B, Ludwig Cobbers JMJ, Büschges R, Wolter M, Knobbe CB, Reifenberger G, Weber RG (2002) Comprehensive analysis of genomic alterations in gliosarcoma and its two tissue components, Genes Chromosom. Cancer 34:416-427. https://doi.org/10.1002/ gcc. 10087

12. Padfield E, Ellis HP, Kurian KM (2015) Current therapeutic advances targeting EGFR and EGFRvIII in glioblastoma. Front Oncol 5:5. https://doi.org/10.3389/fonc.2015.00005

13. Affymetrix Inc, Oncoscan FFPE Assay kit Manual (2013)

14. Affymetrix Inc, CytoScan Assay User Manual (n.d.)

15. Qiagen, Qiagen QIAamp DNA mini kit and Blood Mini Handbook, 5th Ed. (n.d.). https://www.qiagen.com/us/shop/sampl e-technologies/dna/genomic-dna/qiaamp-dna-mini-kit/\#resou rces. Accessed 7 July 72018

16. Invitrogen, Qubit 2.0 Fluorometer Assay Manual, (n.d.)

17. Invitrogen, Qubit 2.0 Fluorometer, (n.d.)

18. Lonza, FlashGel System, (2012)

19. NCBI/NCI/The Cancer Imaging Archive (TCIA) (2015), VASARI (Visually AcceSAble Rembrandt Images) MRI feature set, NCBI/ NCI, Bethesda MD. Available via https://wiki.cancerimagingar chive.net/display/Public/VASARI+Research+Project. Accessed 8 Mar 2017

20. Rupji M, Zhang X, Kowalski J (2017) CASAS: Cancer Survival Analysis Suite, a web based application. F1000Research 6:919. https://doi.org/10.12688/f1000research.11830.2

21. Zhang G, Huang S, Zhang J, Wu Z, Lin S, Wang Y (2016) Clinical outcome of gliosarcoma compared with glioblastoma multiforme: a clinical study in Chinese patients. J Neurooncol 127:355-362. https://doi.org/10.1007/s11060-015-2046-0

22. MetaCore, Regulation of IGF family activity in colorectal cancer, (n.d.). https://support.clarivate.com/LifeSciences/s/article/Metac ore-How-to-cite-Metacore-in-publications?language=en_US

23. MetaCore, Inhibition of apoptosis in pancreatic cancer, (n.d.). https://support.clarivate.com/LifeSciences/s/article/MetacoreHow-to-cite-Metacore-in-publications?language=en_US

24. Kleinschmidt-DeMasters BK, Meltesen L, McGavran L, Lillehei KO (2006) Characterization of glioblastomas in young adults. Brain Pathol 16:273-286. https://doi.org/10.111 1/j.1750-3639.2006.00029.x

25. Yao K, Qi XL, Mei X, Jiang T (2015) Gliosarcoma with primitive neuroectodermal, osseous, cartilage and adipocyte differentiation: a case report. Int J Clin Exp Pathol 8:2079-2084

26. Shelly D, Epari S, Arora I, Pai T, Ahmed S, Moiyadi A, Chinnaswamy G, Gupta T, Goda J, Shetty P, Kane S, Desai S, Jalali R (2016) Epidermal growth factor receptor (EGFR) gene amplification in high-grade gliomas: Western Indian tertiary cancer center experience. Neurol India. https://doi.org/10.4103/00283886.173668

27. Pain M, Wang H, Lee E, Strahl M, Hamou W, Sebra R, Zhu J, Yong RL (2018) Treatment-associatedTP53DNA-binding domain missense mutations in the pathogenesis of secondary gliosarcoma. Oncotarget 9:2603-2621. https://doi.org/10.18632/oncotarget .23517

28. Lin JW, Wu YT, Chang IW (2011) The prognostic impact of O6-methylguanine DNA methyltransferase and epidermal growth factor receptor expressions on primary gliosarcoma: a clinicopathologic and immunohistochemical study of seven cases at a single institution. Indian J Pathol Microbiol 54:683-687. https:// doi.org/10.4103/0377-4929.91491

29. OMIM, CYCLIN-DEPENDENT KINASE INHIBITOR 2A; CDKN2A, (n.d.). https://www.omim.org/entry/600160\#mapping

30. OMIM, CYCLIN-DEPENDENT KINASE INHIBITOR 2B; CDKN2B, (n.d.). https://www.omim.org/entry/600431?searc $\mathrm{h}=\mathrm{cdkn} 2 \mathrm{~b} \&$ highlight $=\mathrm{cdkn} 2 \mathrm{~b}$. Accessed 19 December 2018

31. Nishikawa R, Furnari FB, Lin H, Arap W, Cavenee WK, Huang HJS, Cavenee WK, Huang HJS, Cavenee WK, Arap W, Berger 
MS (1995) Loss of P16INK4 expression is frequent in high grade gliomas. Cancer Res 55:1941-1945

32. Shibahara I, Saito R, Zhang R, Chonan M, Shoji T, Kanamori M, Sonoda Y, Kumabe T, Kanehira M, Kikuchi T, So T, Watanabe T, Takahashi H, Iwabuchi E, Tanaka Y, Shibahara Y, Sasano H, Ishii $\mathrm{N}$, Tominaga $\mathrm{T}$ (2015) OX40 ligand expressed in glioblastoma modulates adaptive immunity depending on the microenvironment: a clue for successful immunotherapy. Mol Cancer 14:1-13. https://doi.org/10.1186/s12943-015-0307-3

33. MetaCore, Role of activation of WNT signaling in the progression of lung cancer, (n.d.). https://support.clarivate.com/LifeS ciences/s/article/Metacore-How-to-cite-Metacore-in-publicatio ns? language $=$ en_US

34. Vibhakar R, Foltz G, Yoon J, Field L, Lee H, Ryu G, Pierson J, Davidson B, Madan A (2007) Dickkopf-1 is an epigenetically silenced candidate tumor suppressor gene in medulloblastoma1. Neuro-Oncology 9:135-144. https://doi.org/10.1215/15228 517-2006-038

35. Shou J, Ali-Osman F, Multani AS, Pathak S, Fedi P, Srivenugopal KS (2002) Human Dkk-1, a gene encoding a Wnt antagonist, responds to DNA damage and its overexpression sensitizes brain tumor cells to apoptosis following alkylation damage of DNA. Oncogene 21:878-889. https://doi.org/10.1038/sj.onc.1205138

36. Soubannier V, Stifani S (2017) NF-кB signalling in glioblastoma. Biomedicines 5:29. https://doi.org/10.3390/biomedicines5020029

37. Friedmann-Morvinski D, Narasimamurthy R, Xia Y, Myskiw C, Soda Y, Verma IM (2016) Targeting NF-kB in glioblastoma: a therapeutic approach. Sci. Adv. https://doi.org/10.1126/sciad v. 1501292

38. MetaCore, Lysophosphatidic acid signaling via GPCRs, (n.d.). https://support.clarivate.com/LifeSciences/s/article/MetacoreHow-to-cite-Metacore-in-publications?language=en_US

39. Fortin Ensign SP, Mathews IT, Symons MH, Berens ME, Tran NL (2013) Implications of Rho GTPase signaling in glioma cell invasion and tumor progression. Front. Oncol 3:1-11. https://doi. org/10.3389/fonc. 2013.00241

40. Bhatlekar S, Fields JZ, Boman BM (2014) HOX genes and their role in the development of human cancers. J Mol Med 92:811823. https://doi.org/10.1007/s00109-014-1181-y

41. Duan R, Han L, Wang Q, Wei J, Chen L, Zhang J, Kang C, Wang L (2015) HOXA13 is a potential GBM diagnostic marker and promotes glioma invasion by activating the Wnt and TGF- $\beta$ pathways. Oncotarget 6:6. https://doi.org/10.1136/bmj.2.4933.263-b

42. Schmid RS, Simon JM, Vitucci M, McNeill RS, Bash RE, Werneke AM, Huey L, White KK, Ewend MG, Wu J, Miller CR (2016) Core pathway mutations induce de-differentiation of murine astrocytes into glioblastoma stem cells that are sensitive to radiation but resistant to temozolomide. Neuro-Oncology 18:962-973. https://doi.org/10.1093/neuonc/nov321

43. Svoboda LK, Bailey N, Van Noord RA, Krook MA, Harris A, Cramer C, Jasman B, Patel RM, Thomas D, Borkin D, Cierpicki $\mathrm{T}$ (2017) Tumorigenicity of Ewing sarcoma is critically dependent on the trithorax proteins MLL1 and menin. Oncotarget. 8(1):458

44. Svoboda LK, Harris A, Bailey NJ, Schwentner R, Tomazou E, von Levetzow C, Magnuson B, Ljungman M, Kovar H, Lawlor ER (2014) Overexpression of HOX genes is prevalent in Ewing sarcoma and is associated with altered epigenetic regulation of developmental transcription programs. Epigenetics 9(12):1613-1625

45. Small U, Round B, Sarcomas C (2016) Novel BCOR-MAML3 and ZC3H7B-BCOR gene fusions in undifferentiated small blue round cell sarcomas. Katja 40:433-442. https://doi.org/10.1097/ pas.0000000000000591.novel

46. Gladson CL, Prayson RA, Liu WM (2010) The pathobiology of glioma tumors. Annu Rev Pathol Mech Dis 5:33-50. https://doi. org/10.1146/annurev-pathol-121808-102109

47. Tabuchi S (2015) The autotaxin-lysophosphatidic acid-lysophosphatidic acid receptor cascade : proposal of a novel potential therapeutic target for treating glioblastoma multiforme. Lipids Health Dis. https://doi.org/10.1186/s12944-015-0059-5

48. Manning TJ, Parker JC, Sontheimer H (2000) Role of lysophosphatidic acid and rho in glioma. Cell Motility 199:185-199

49. Ferluga S, Debinski W (2015) HHS Public Access 32:190-201. https://doi.org/10.3109/08977194.2014.985787.Ephs

50. Sigismund S, Avanzato D, Lanzetti L (2018) Emerging functions of the EGFR in cancer. Mol. Oncol. 12:3-20. https://doi. org/10.1002/1878-0261.12155

51. Ålgars A, Lintunen M, Carpén O, Ristamäki R, Sundström J (2012) Reply: eGFR alterations and response to anti-EGFR therapy: is it a matter of gene amplification or gene copy number gain? Br J Cancer 106:428. https://doi.org/10.1038/bjc.2011.570

52. Newman S (2015) Interactive analysis of large cancer copy number studies with Copy Number Explorer. Bioinformatics 31:2874 2876. https://doi.org/10.1093/bioinformatics/btv298

53. Smith DR, Wu CC, Saadatmand HJ, Isaacson SR, Cheng SK, Sisti MB, Bruce JN, Sheth SA, Lassman AB, Iwamoto FM, Wang SH, Canoll P, McKhann GM, Wang TJC (2018) Clinical and molecular characteristics of gliosarcoma and modern prognostic significance relative to conventional glioblastoma. J Neurooncol 137:303-311. https://doi.org/10.1007/s11060-017-2718-z

Publisher's Note Springer Nature remains neutral with regard to jurisdictional claims in published maps and institutional affiliations.

\section{Affiliations}

\section{Lindsey Lowder ${ }^{1}$ (1) Jennifer Hauenstein ${ }^{2} \cdot$ Ashley Woods $^{3} \cdot$ Hsiao-Rong Chen ${ }^{4} \cdot$ Manali Rupji $^{4}$ - Jeanne Kowalski ${ }^{5}$. Jeffrey J. Olson ${ }^{6} \cdot$ Debra Saxe $^{7} \cdot$ Matthew Schniederjan $^{8} \cdot$ Stewart Neill $^{1} \cdot$ Brent Weinberg $^{9} \cdot$ Soma Sengupta $^{10}$}

Jennifer Hauenstein

jennifer.hauenstein@emoryhealthcare.org

Ashley Woods

Acwood2@emory.edu

Hsiao-Rong Chen

hsiao-rong.chen@emory.edu

Manali Rupji

manali.rupji@emory.edu
Jeanne Kowalski

Jeanne.kowalski@austin.utexas.edu

Jeffrey J. Olson

jolson@emory.edu

Debra Saxe

Dsaxe01@emory.edu

Matthew Schniederjan

mschniederjan@emory.edu 
Stewart Neill

sgneill@emory.edu

Brent Weinberg

Brent.d.weinberg@emory.edu

Soma Sengupta

Soma.sengupta@emory.edu

1 Department of Pathology \& Laboratory Medicine, Emory University Hospital, H185D, 1364 Clifton Road, NE, Atlanta, GA 30322, USA

2 Department of Oncology Cytogenetics, Emory University Hospital, F143A, 1364 Clifton Rd. NE, Atlanta, GA 30322, USA

3 Department of Hematology/Oncology, Winship Cancer Institute, 1365 Clifton Rd. NE, Atlanta, GA 30322, USA

4 Bioinformatics \& Biostatistics, Winship Cancer Institute, 1365 Clifton Rd. NE, Atlanta, GA 30322, USA
5 Department of Oncology, Dell Medical School, LIVESTRONG Cancer Institutes, The University of Texas At Austin, 1601 Trinity St., Bldg. B, Stop Z1100, Austin, TX 78712, USA

6 Department of Neurosurgery, Winship Cancer Institute, Emory University, 1365 Clifton Rd. NE, Atlanta, GA 30322, USA

7 Department of Oncology Cytogenetics, Emory University Hospital, 1364 Clifton Rd. NE, Atlanta, GA 143A, USA

8 Department of Pathology \& Laboratory Medicine, Children's Healthcare of Atlanta, Emory University Hospital, H185D, 1364 Clifton Road, NE, Atlanta, GA 30322, USA

9 Department of Neuroradiology, Emory University Hospital, BG20, 1364 Clifton Road, NE, Atlanta, GA 30322, USA

10 Departments Neurology, Hematology \& Medical Oncology, Winship Cancer Institute, Emory University, 1365 Clifton Rd. NE, Atlanta, GA 30322, USA 